\title{
Revealing Strengths, Weaknesses and Prospects of Intelligent Collaborative e-Learning Systems
}

\author{
Amal Asselman*, Azeddine Nasseh, Souhaib Aammou \\ LIROSA, Faculty of Sciences, Abdelmalek Essaadi University, Tetouan, 93 000, MOROCCO
}

\begin{tabular}{l} 
A R T I C L E I N F O \\
\hline Article history: \\
Received: 09 April, 2018 \\
Accepted: 02 May, 2018 \\
Online: 20 May, 2018 \\
\hline Keywords: \\
Artificial intelligence \\
Collaborative e-Learning \\
Adaptive hypermedia techniques \\
Cognitive user model \\
Multi-agent Systems \\
E-Learning systems
\end{tabular}

\section{Introduction}

The evolution of the Internet and the development of educational content have led to the emergence of a new mode of education called e-Learning (electronic learning). This mode is used in several areas including employee training follow-up or self-training. E-Learning tends to develop around the world following the evolution of new Information and Communications Technologies (ICT) in the educational field that allows him to have many advantages such as the ability to facilitate teaching, and the accessibility of educational resources. This mode of learning is based on remote access to the provision of educational resources and learning services. The online learning environments are recognized by a whole different set of appellation vary according to the tasks assigned to them. Those environments remain in constant evolution, we cite WBT (Web-Based Training), LMS (Learning Management System), LCMS (Learning Content

*Corresponding Author: Amal ASSELMAN, LIROSA, Faculty of Sciences, Abdelmalek Essaadi University, Tetouan, 93 000, MOROCCO

E-mail : asselman.amal@gmail.com
Management System) CLCS (Computer Support for Collaborative Learning), MOOC (Massive Open Online Course) etc.

Generally, the analysis of e-Learning systems based on their characteristics and functionalities [1] [2] mention that each of them is credited for enhancing the acquisition of learners. They offer them the opportunity to learn using a modern, fun, and interactive strategies that are completely different to traditional learning in which requires the memorization of a set of knowledge to better get them back on the day of examination. These programs also gives to the learner the choice of lessons that meet his needs without obligation to follow the lessons imposed by the teacher.

Despite all their benefits, these systems have recognized a major obstacle due to poor management of learning time and lack of orientation on the platform. In addition, the geographical dimension causes a difficult finding of available human accompanist in e-Learning environment during the whole day and throughout the learning period. Moreover the difficulty of finding always learners with the same profile available to collaborate. As a result, the learner can simply be lost depending on the huge number of resources and links. In fact, this eventually leads him to 
feel that online training is boring and decide automatically to drop out.

According to the reason mentioned before, several statistics [3] [4] [5] [6] have been realized showing us the number of students training leave, as example Figure 1 concerning "MITx course, $6.002 x$ (Circuits and Electronics)" available on edX online learning platform [7]. This example indicates the number of learners participated during all phases of the training. It illustrates that there is a high drop-out rate appears from the first week. And after completing the 14 weeks of study, it remains a few of student arrive to accomplish this course. In terms of numbers, there are approximately just $4.6 \%$ of students have succeeded while the $95.4 \%$ withdrew.

\section{MITx Circuits and Electronics 6002x}

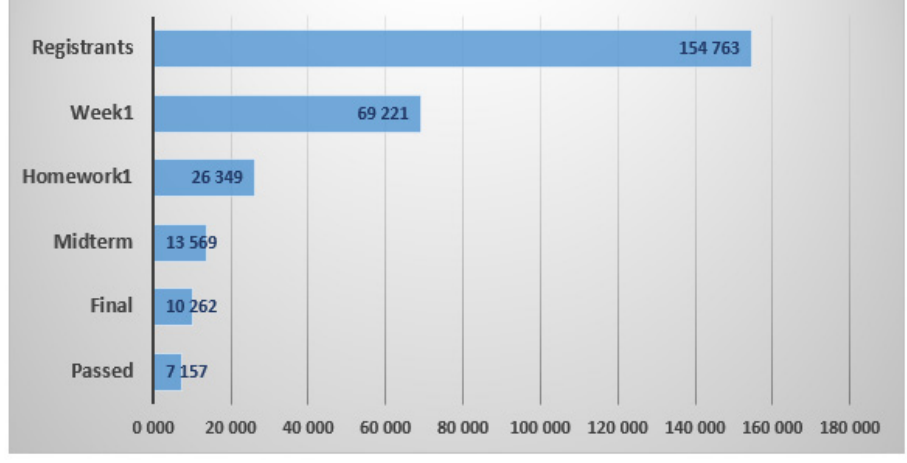

Figure 1: Dropout rate among those who initially registered [7]

Consistent with this context and precisely with the accelerated development of information technologies as well as the trend towards the use of smart devices, the integration of artificial intelligence makes a great change in the society in the context of Collaborative e-Learning Systems. It remains as an appropriate solution to make educational system more productive, persistent and efficient [8]. It allows the creation and extension of various intelligent technologies such as adaptive hypermedia techniques, agent technology, and web services which makes e-Learning more effective and flexible. In the same case, the use of Multi-agent Systems (MAS) technology in the design and modeling process of learning environments has evolved spectacularly. It proved its ability in modeling the different actors of e-Learning systems and managing their interactions to meet their dynamic and execution needs by their innovative features like intelligence, autonomy, reactivity, social ability, and proactivity. However, even though there are collaborative e-Learning environments using the mentioned technologies, they have structured with a minimum of consideration the relevant aspects of human cognitive architecture, a low capacity to assess the help provided by learners and several other weaknesses.

This paper, as an extension of work originally presented in 15 th International Conference on Emerging eLearning Technologies and Applications (ICETA) [9], is organized as follows. Section 2 presents general principles of collaborative online learning by presenting the different activities of e-Learning system's actors as well as the interaction between them. Section 3 presents an overview of distributed artificial intelligence, multi-agent systems, and adaptive systems in order to indicate their importance for improving the educational systems. Section 4 is based on an analysis presenting the advantages, the limitations of some existing agent-oriented collaborative learning system, and comparison between them on the basis of a multitude of criteria: collaboration features, intelligent actors interaction, adaptability measurement, cognitive student modeling, and security measurement. In the last, we will present certain recommendations in order to indicate how can improve these systems for stopping the main reason for dropout.

\section{Collaborative e-Learning Systems}

\subsection{Features and advantage of e-Learning}

E-learning becomes an essential part of modern education that allows learners to consult the pedagogical content effectively everywhere and any time [2]. These contents are organized into modules that can be assembled into personalized training courses. Currently, many studies show that e-Learning training has better results compared to traditional classroom training. It is considered as an efficient and attractive way for computer education delivered or mediated a pedagogical content and learning experiences by means of digital technologies. These systems are recognized as a software environment designed, specifically, to meet the needs of distance education and to allow organizing the online content in which the authors have a simple interface to deposit their contents (within predefined themes and organized in categories). They can associate one or several downloadable files to their courses [2]. These systems are characterized by a number of advantages like:

- The ease of sharing, exchanging and using varied learning modalities (audio sequences, videos, animations, diagrams);

- Flexibility and adaptability according to learner availability (By providing training at any time or by allowing the learner to learn at his/her own pace and in an individualized way);

- The relative reduction of costs for learners and trainers (elimination of accommodation and travel costs) and increased accessibility of training.

E-Learning follows a new economic model of production in which a large number of people join with new communication tools. Learning is an active process where tutor plays a leading role in training to help advance learners by placing more emphasis on monitoring, accompanying rather than transferring expertise. The e-tutor occupies several goals, for example, he animates the group or the community of learners, he determines the most adapted training course to learners, he offers him the help in his first steps and he ensures the pedagogical follow-up of the training (personalized advice, analysis of the progression, answers to the questions of the learners). As in traditional learning systems, the teacher was previously the sole holder of knowledge. However, in modern e-Learning systems, his role is to facilitate learning by guiding learners to make good use of knowledge [10]. He can also observe the progress of student's activities in order to motivate and guide them during their prevent failure or abandonment. Moreover, the role of the learner is no longer similar to his / her role in traditional learning which is limited to the memorization and evaluation of his knowledge on the day of the exam, but he governs his process learning by transforming information into 
knowledge and creating interactions with other members of the group. Before learning, students set goals and learning tasks of the plan. During learning, they work together to accomplish tasks and monitor their progress. And after learning, they evaluate their performance and plan for future learning [1].

Online education systems revolve around a set of functionalities such as:

- Administrative management of the platform. It concerns the management of registration in training and the management of administrative data training.

- Creation of courses and training plans (creation of teaching scenarios, curricula, and preparation of the various evaluation tests) besides changing or add course content and activities, schedule management and training path planning.

- It allows classification, indexation, and administration of pedagogical materials. As well as consultation of educational content, individualization of learning and communication between trainers and learners and between learners.

- It determinate roles of trainers, groups of students and their access by specifying content types, communication modes, test types, and by facilitates communication with students or between them by messaging or forum.

- It authorizes creation and modification of individualized training paths as well as follow-up of the activities of learners on the platform (time spent online in the course notes, dialogues, work deposited on the platform...).

E-learning researchers aim to improve distance learning systems in two areas: organizationally and functionally. The first by taking note the standardization of self-training materials and a quality approach, providing training opportunities and broadening the prospects for dissemination to employees, suppliers, and customers [1]. The second by trying to personalize the learner's profile according to training, to reduce costs, to save time and to make learning more effective.

\subsection{Definition and principles of collaborative learning}

Since the evolution of the web, the semantic field of the word "collaboration" has evolved considerably. Several education experts point out that school is not just a place to learn facts. It is a place for a student to interact with one another and learn the basics of communication, etiquette, and respect for others. Actually, many studies have focused on the collaborative e-Learning system that is defined as the learning strategy where several learners interact with their partners, share ideas and help each other to achieve their common goals [11]. These educational environments are designed and dedicated to encouraging individual work and group work in various fields involving the domain of instruction. In the same context, Andrew Carnegie as an American Industrialist and philanthropist define collaborative work as follows:

"Teamwork is the ability to work together toward a common vision. The ability to direct individual accomplishment toward organizational objectives. It is the fuel that allows ordinary people to achieve extraordinary results".
In collaborative e-Learning, actors can work together regardless of geographic location or time limitation. In other words, it provides learners with a great flexibility of time and place as well as excellent asynchronous interaction [12]. This mode of learning follows a learner-centered approach by involving new roles for teachers, accompanists, and learners. It can be reported that students can undertake problems that are more complicated and gain a better understanding of the material by working collaboratively [13]. For that, learning content is becoming increasingly hypermedia intelligent and collaborative, which allows placing initiative and power in the hands of learners to access the information. Moreover, this system makes the responsibility of collective and global learning. Indeed all members of the group stay in regular contact, each learner must participate in the group in an action to be realized, each member can contribute to the action of other members of the group to increase its performance. According to Walckiers and De Praetere in the case of collaborative work, there is no a priori distribution of roles: individuals are gradually subsumed into a group that becomes an entity in its own right [14].

Generally, Collaborative e-Learning provides functionalities essential in the educational process, such as real-time, as well as offline data and information gathering, analysis and distribution, embedded feedback, assessment, and collaboration. All of these functionalities are based on synchronous and asynchronous learning tools for interaction [15]. Where synchronous tools allow real-time communication between people remotely geographically: instant messaging, voice telephony, audio conferencing and video conferencing, etc. Indeed, the actors must be at the same time facing their respective computers. While asynchronous tools allow for time-and-space exchanges are email, forum discussions, portfolio, wiki, and blog. In this type of system when a person sends a message, the receiver can read it for a few minutes, hours or days later.

Accordingly, Collaborative learning is a construct based on several sources. It feeds on the values of constructivism and relies on cognitive theories to explain the mechanisms of learning. For this reason, it promotes the integration of students in homogeneous groups which have the same profile and the common cultural and social aspects. This integration allows the development of critical thinking in the learner, as well as the emotional and pedagogical support of weak students. That can create for learners a source of motivation and consequently increase the communication skills, it can also support the realization of a continuous formative evaluation.

\section{Artificial Intelligent technologies For Education}

John McCarthy, an American computer and cognitive scientist pioneer and inventor, was known as the father of Artificial Intelligence (AI). The term AI was proposed, in 1956, by this person in Dartmouth Artificial Intelligence conference [16]. It was the first artificial intelligence conference organized to draw the talent and expertise of others interested in machine intelligence for a month of brainstorming. It refers to the ability to interact with the user and respond to their actions in a natural way [17]. It is recognized as a computer discipline that aims to model or simulate so-called intelligent human behaviors such as perception, memorization, decision-making, understanding, and learning [16]. 
Among the areas where artificial intelligence is ready to make big changes is the field of education. The application of AI to eLearning content is not just a cost-saving solution; it also opens up a whole new way of looking at learning itself.

Several advanced research has been done in this area, particularly in the field of intelligent tutorial systems (ITS) so that research aims primarily at making learners benefit from technological advances in artificial intelligence. It can adapt educational software to student needs by putting more emphasis on certain subjects, repeating things that students haven't mastered, and generally help students to work at their own pace [17]. AI will shift the role of the teacher to that of a facilitator so that teachers will supplement AI lessons, assist students who are struggling, and provide human interaction and hands-on experiences for students. AI-driven programs can give students and educators helpful feedback by allowing students to get the support they need and choose majors based on the areas they are doing well. And by providing for teachers ability to find areas where they can improve teaching for students who may be struggling with the subject. Data powered by AI can change how schools find, teach, and support students as well as it can point out places where courses need to improve. It also may change where students learn, who teaches them, and how they acquire basic skills [18]. Similarly, it is altering how can find and interact with information. In like manner, AI can make trial-and-error learning less intimidating in view of the idea of not knowing the answer or even failing is crippling. For this, artificial intelligence could help students learn in a relatively non-judgmental environment, especially when AI trainers can offer improvement solutions.

So, the use of artificial intelligence remains as an appropriate solution to make educational system more productive, persistent and efficient [8]. In order to achieve this intelligence, it must be aware of the user's objectives and knowledge for the purpose of designing adaptive educational intelligent systems. These systems try to help users during their learning by limiting the browsing space, suggesting the most relevant links to follow, or providing adaptation comments to visible links [19]. Add to that, integration of multi-agent systems offer an original approach to designing intelligent and collaborative systems. Multi-agent systems are characterized by the distribution of global control of the system, and by the presence of autonomous agents evolving in a shared and dynamic environment. They are more adapted to designing a learning environment where each member must manage and exchange knowledge, and collaborate with others to achieve its goals [15]. The fundamental aspects of these intelligent e-Learning systems are the ability of perception, inference, learning, reasoning, and knowledge-based systems [20], resulting from the integration of the agents' cognitive architecture. This latter aims to treat the process of development and use of knowledge through the set of mechanisms of human cognition. In other words, it models specific tasks based on the simulation of human behavior to create a model able to understand, reason, and solve problems [21].

Due to the benefited of artificial intelligence, we will be interested in the modeling of intelligent behaviors that are the product of the cooperative activity between several agents in order to design an adaptive system respecting the personal needs of each learner and to have agents capable of interacting similarly to humans thanks to the integration of cognitive architecture.

\subsection{Agent and Multi-Agent System in education}

The design of a distance learning system involves a complex set of processes that are sometimes difficult to associate in a coherent and evolving system. Multi-agent systems (MAS) are proving to be relevant for solving these types of problems thanks to its great ability to structure knowledge transfer systems and open new perspectives of assistance to distance learning. MAS is currently considered as the most active research discipline which they relate to several areas, in particular of artificial intelligence, distributed computing systems, robotics and software engineering. These systems are made up of several flexible and autonomous entities interacting with each other and called agents. According to Ferber, a multi-agent system can be considered as a macro-system composed of autonomous agents that interact in a common environment in order to achieve a coherent collective activity [11].

In literature, the notion of agent remains relatively vague to define. It is found that several researchers have defined this concept in different ways. All of these definitions look the same, but they also differ according to the application context for which the agent is designed. According to Ferber, an agent is defined as a physical or virtual entity, autonomous, located in an environment, capable of acting in an environment, communicating with other agents, perceiving its environment, reproducing itself [11]. This definition is supported by Wooldridge [22] in which present an agent as computer system located in a certain environment capable of autonomously performing actions in that environment, achieve its goals. Another frequently cited definition is presented by Russel [23]; he provides that an agent is all that can be seen as perceiving its environment through sensors and acting on this environment through effectors. Generally, agents aim to reduce the complexity of problem-solving time by dividing it into sub-problems, each sub-problem is assigned to an independent intelligent agent called "resolver". To achieve this, agents are organized, negotiated and coordinated for the purpose of resolving a common goal [24].

Generally, Educational area based on multi-agent systems presents a series of advantages for reason that these systems have inherited the traditional benefits of distributed resolution and artificial intelligence. Among which we can mention that intelligent systems are open, i.e. they have the ability to dynamically add or remove features or services in the agent system. It recognized a flexibility of the computer tool which aims to make the programming simpler, to change agents' behavior, and to add or to delete possible actions. They also have the advantage of the decentralization of the agents which aims at allowing to support the individual failure of these elements as well as distributed problem solving where a problem can be broken down into subparts, each of which can be solved independently to arrive at a stable solution. Moreover the speed of execution where several agents can work at the same time for the resolution of a problem thanks to the parallelism of execution.

\subsection{A required architecture for e-Learning system}

In order to build an intelligent educational system that is able to minimize the intervention of a human in the execution of tasks, to facilitate localization and customization of appropriate elearning resources, thus to promote collaboration in e-learning environments, as well as to be able to automate effectively learning 
and administration tasks, and behave axially like a human, it is necessary to implement an architecture containing agents able to act similarly as human users. To achieve this goal, the characteristics of each type of agent must be specified.

Agents can be classified based on the technology used to implement it, on the type of the agent or on the application domain itself. According to Wooldridge, agents can often be categorized according to their individual behaviors. Generally, two main categories of agents can be distinguished [22]:

- Reactive agents: have not any representation of other agents or their own environment as well as their inability to account for its past actions. They behave in a "stimulusresponse" way in the face of what they perceive. This kind of agents argues that it is not necessary for agents to be intelligent individually for the system to behave intelligently [11]. In general, this category of agents only has a reduced communication protocol, which shows its weak communication capacity [25].

- Cognitive agents: are most represented in artificial intelligence distributed field. They are composed of a set of agents "intelligent" that include memory, attention, communication, and learning. Each agent has a knowledge base comprising all information and know-how necessary to carry out its task and to manage interactions with other agents and with its environment [26]. These agents have a global representation of themselves, their environment and other agents with whom they communicate. In addition, they also have an explicit representation of beliefs, desires, and intentions.

This description shows that an agent is capable of acting autonomously according to the goals that it pursues. Thus it can be seen that cognitive agents are more beneficial than reactive agents. Where the latter impose more rigid behaviors, which shows that reactive agents are not very powerful since they are reduced to their own means [26]. Moreover, it does not have a complete representation of its environment and other agents. For that, we can summarize that the most appropriate architecture for an intelligent education system is the one that uses a set of human cognition mechanisms based on cognitive agents. And consequently, due to their performance, the integration of this type of agent allows the system implemented to benefit the use human knowledge process. Specifically, it is based on the simulation of human behavior to create a model capable of memorizing, learning, understanding, reasoning, and solving problems [27].

The e-Learning's cognitive architecture defines the manner in which a cognitive agent (learners, administrators, trainers ...) manages the resources that it has primitive. According to Anderson "A cognitive architecture is a specification of the structure of the brain at a level of abstraction that explains how it achieves the function of the mind" [28]. According to [27], we compared between a set of cognitive architecture and conducted a detailed functional comparison by looking at a wide range of cognitive components, including perception, goal representation, memory types, learning mechanism and problem-solving method. This comparison and other similar analyses [29] [30] [31], defined ACT-R as is the most appropriate architecture for e-learning systems which it allows to have a behavior more identical to that of a human compared to the other architectures. ACT-R is applicable with multiple domains. In Fig. 2 we distinguish some of their application.

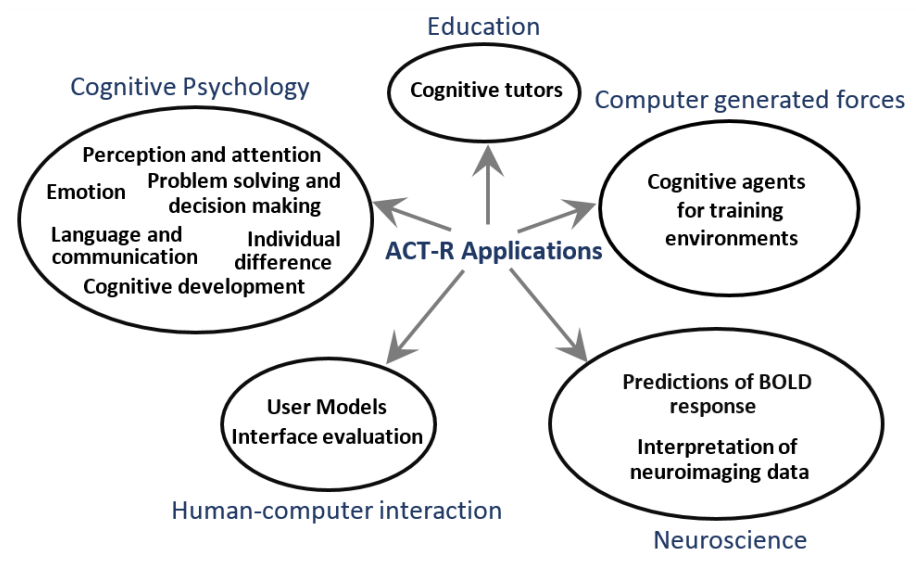

Figure 2: The main applications of cognitive architecture ACT-R

Recently, researchers on Cognitive science focus on the working process of the human brain that is resembled in various real-time applications. They show that the design of a learning system that is based on the integration of Anderson's ACT-R learning theory could be able to properly analyze a learner's behavior and know his or her cognitive state. It considerate each student has a cognitive profile and which can help the individual to be able to develop his or her learning skills and strategies in the light of useful self-knowledge. The system should learn like a human and should recognize the new skill, which is the main objective of cognitive science.

\subsection{Adaptive learning}

Adaptive hypermedia is a field that recognizes a strong use of artificial intelligence. The most popular hypermedia systems are related to the pedagogical field [32]. The hypermedia educational systems allow the creation of adaptive documents in order to establish some form of a dialogue between users and system. These documents stored on a computer support, as types of nodes connected by links [33]. Such systems offer to users the possibility to navigate in the hyperspace by allowing them to create their own educational path. The construction of the hypermedia is started when learner connects to visualize a course. In particular, the generation of content starts when the learner decides to activate a concept he wants to follow, or when he clicks on a hypertext link that leads him to another concept of the same course or another course [34].

In general, there are two kinds of hypermedia systems differ in the manner of adaptation: The adaptable hypermedia system and the adaptive hypermedia. The adaptable hypermedia offers to the learner the opportunities to configure the system by changing certain parameters, and consequently, this system can adapt its behavior [34]. The adaptive hypermedia system is characterized by its ability to update dynamically the user's profile during all phases of learning. This adaptation is done in different ways, either by using the user's navigation actions or by analyzing his answers to the questionnaires, it can be also based on the initial information provided by the user to adapt the nodes and navigation [34]. 
Moreover, the system can track and analyze the learner behavior and save it in a user model in order to adapt automatically the presentation consequently according to the characteristics of this model [35].

An educational hypermedia system is a system capable of adapting itself to the different characteristics of the students that are specified through a model. Brusilovsky [33] specifies that "Adaptive hypermedia systems are hypermedia systems which reflect some features of the user in a user model and use this model by adapting various visible aspects of a system to user". Adaptive hypermedia aims to improve education systems by enhancing the assimilation of knowledge through the adaptation of links, content, and presentations to the user. These systems can considerably reduce the user's path in hyperspace in order to avoid disorientation of user and the risk of misunderstanding the document.

An adaptive teaching system implements mechanisms that leverage on domain knowledge, learner knowledge, and knowledge about learning processes. This adaptive teaching offers approaches and personalized educational content. Usually, in order to increase the profitability of an educational application for a learner or a group of learners that have different profiles, it is obviously necessary to adapt the system according to learner goals, characteristics, and interests. This adaptation can be done in two ways: presentation adaptation and navigation adaptation. The first kind of adaptation makes it possible for each user to view a personalized page that is different from that of the others [11]. Where the navigation adaptation is interest in helping learners to find their self in hyperspace or to oblige them to use certain links rather than others in order to follow the most relevant path [19]. This phase involves changing the navigation structure or defining how this navigation structure will be presented to the user.

Learner modeling aims to give a complete and faithful description of all aspects of the user's behavior. It represents the core of adaptive learning system. When a learner takes training in a distance learning session, the learner model evolves according to learners' educational backgrounds and their responses [21]. This information can be directly entered by the learner (response to questions asked by the system), calculated from results of exercises or tests, or deduced from the learner's behavior in terms of interaction with the system (navigation choice, document reading time, etc.). This model aims to present all the characteristics of learners helping to achieve adaptation [36]. Those characteristics are separated in learner model into two categories [26]: Domain Dependent Data and Domain Independent Data. The first reflects the status and level of knowledge and skills which student achieved in a certain subject and at the certain moment of time. This category is organized by a set of elements (concept, topic, subject...). The second includes information about the learner skills based on his behavior. This category may include generic information (demographic information, learner learning goals, interests, background and experience) and psychological information such as memory, perception, learning style and preferences, decision making abilities, critical thinking, analytical thinking for modeling cognitive aptitudes, and motivation, reflection, self-awareness, self-assessment, self-monitoring, selfregulation for modeling metacognitive affective features...) [31].

\section{Analysis of Agent-Oriented Collaborative Learning System}

\subsection{Existing intelligent collaborative e-Learning system}

Many multi-agent systems that focus on the collaborative eLearning domain have been designed and implemented by integrating a wide range of functionalities. These systems offer an original approach to designing intelligent systems and provide an interesting solution for both problems of structuring and exploiting knowledge. Agent-oriented collaborative learning system offers many appropriate tools for designing a learning environment where each member must manage and exchange knowledge and then to collaborate with others in order to achieve its goals. The common goal of these systems is to improve the learning ability of the student/learner., among which we can distinguish. In the field of scientific research, there are several systems that meet these objectives. In this paragraph, we will present and analyze them it in order to clarify their strengths and limitations.

\subsubsection{ALLEGRO}

ALLEGRO is an intelligent environment [37]. This system offers flexibility, autonomy, and adaptability to the e-Learning environment base on MAS. It offers an individualized learning as well as CSCL (Computer Supported Collaborative Learning) which makes the system capable of supporting collaborative learning. This system is based on three theories of learning behaviorism, cognitivism, and historic-social.

This system has six types of artificial agent:

- Student Agent: aims to manage the learning student model and maintains individualized information about the apprentice.

- Tutor Agent: will guide the learning process, decides what action to teach, how and when, It tries to detect mistakes in the process of the apprentice, in addition, it offers suggestions, critics, and recommendations through the selection of the suitable pedagogical strategy. This agent aims to promote learner learning by asking Agent Diagnosis to send to the apprentice an appropriate evaluation according to its profile. Or by asking Expert Agent to offer certain knowledge to the learner according to the plan and its diagnosis.

- Diagnosis Agent: is responsible for filtering and classifying the knowledge level of the learner.

- Expert Agent: manages the content of the area or specific subject of learning and teaching. It sends knowledge to the apprentice when he asks for it or at the request of the Tutoring Agent.

- Collaboration Agent: aims to group the apprentices by study topics, profiles or behavior and that's why it tries to find students who are interested in the same subject in order to create synchronous or asynchronous collaborative communication.

- Interface Agent: allows interaction between the user and the artificial agents. It allows the unfolding of knowledge and collaboration on the screen of the student. 


\subsubsection{BAGHERA}

BAGHERA is a platform for distance learning [38]. This platform has been implemented with the JATLite multi-agent application development environment. It proposes the basics of computer environments for human learning (EIAH) seen as an educational community made up of human and non-human agents who cooperate and work together to train students. Its functional objective is to construct a logical experimental, flexible, and adaptable platform for distance education. Its high-level MAS is used for collecting what is needed for its pedagogical behavior, while its lover level MAS is responsible to diagnose student's conception. These diagnoses are based on the student's action towards the Interface

In the environment, each apprentice is supported by three types of agents:

- Companion-Student Agent: aims to make the link with the rest of the system and the students. Also through this agent, the student can access his electronic binder and a specific graphical interface that will allow him to work on one of his exercises, save his work and request a verification of the proof he develops.

- Mediator Agent: Chooses an appropriate agent to send the student's solutions for verification.

- Tutor Agent: He is an artificial designer. This agent is mandatory for every student registered in the system. When the teacher is absent, the tutor agent takes charge of the pedagogical follow-up for autonomous learning with regard to his student and the learning situation.

Similarly, the teacher is supported by two types of agents:

- Companion-Teacher agent: allows realizing the interface between the system and the teacher. It ensures the access of the teacher to his electronic locker. The teacher relies on the Companion-Teacher agent to connect with the students and other teachers who are available.

- Assistant Agent: The main function of this agent is to manage the teacher's record that contains all the exercises. The agent also manages the distribution of these exercises. For this purpose, he distributes them to the tutor agents who then transmit them at the appropriate time in the electronic binders of their students.

\subsubsection{I-MINDS}

Intelligent Multi-agent Infrastructure for Distributed Systems (IMINDS) [39]. It provides a multi-agent infrastructure for Computer-Supported Collaborative Learning (CSCL) that is capable of monitoring and tracking both students and teacher activities and making decisions to support the users. This system allows the learner to learn, interact with other learners as well as with the tutor and it also allows it to form a group. I-MINDS provides standard online collaborative features. The infrastructure is also capable of machine learning, allowing the agents to improve their performance over time or to adapt to individual user behaviors [39]. In this system, intelligent agents interact to serve tutors and learners. I-MINDS provide collaboration in two principle manner: forum and whiteboard. During Forum www.astesj.com communication, student agents recognize some aspects of tracked behaviors including the number of messages each student contributed to the forum, the average length of each message, and the average quality of each message. Also during whiteboard collaboration, student agents track behaviors including the time that each student spent on the whiteboard and the tools (e.g., annotation, drawing, and eraser). This architecture provides to a teacher the ability to send their lectures directly from the classroom to the students via whiteboard technology. I-MINDS consists of three intelligent agents:

- Student Agent: manages the interaction channels among students and exchange information between the teacher and the students and the group agent. The student agent presents the learning material to the student. It can also assess and form a buddy group for the student that it serves. Other aspects of tracked behaviors include the number of messages each student contributed to the forum, the average length of each message, and the average quality of each message;

- Group Agent: is designed to encourage collaborative learning groups. It controls the students' interactions to assess each student's contribution as a group member.

- Teacher Agent: interacts with a teacher. It is responsible for disseminating information streams to student agents, maintaining profiles for all students, assessing the progress and participation of different students, ranking and filtering the questions asked by the students, and managing the progress of a classroom session.

\subsubsection{MASCE}

MASCE is the acronym of Multi-Agent System for Collaborative E-learning, it is a system described in [40]. It is intended in a blended learning to be used to support teaching and learning processes and also to encourage students to collaborate with peer to learn. The analysis and design phase of this system is done using Beliefs, Desires, Intentions-Agent Based Software Development (BDI-ASPD) to solve a particular problem in agent programming.

This system consists of three main intelligent agents:

- Student agent: helps the learning process of students. It provides the mechanism for initialized and update the student's profile and preferences by tracking student behavior. During the learning process, once a student registers to follow a new course, a student agent dedicated to that course is created.

- Instructor agent: has the ability to interact with the students as well as allowing a group of students to work on the same assignment. It provides pedagogical materials when requested by Assistant Agent for distributing to students' agents, evaluates the progress and participation of different students, and maintains course progress.

- Assistant agent: plays the most essential role in the proposed system. It is initialized as soon as any of the users start to use the system and acts as a mediator between Instructor Agents and Student Agent of a specific course. 
It can also track the user's preferences in different areas then can nominee a peer for the user to get help.

MASCE allows the learner to review course materials, ask for help and evaluate the help provided to enable the system to have a list of best assistants [40]. Also, it allows students interacting with their tutors or the other learners using collaboration services provided: forums, wikis, blogs, chat rooms, e-mails. Hierarchical clustering algorithms are used for matching to find the best candidate helper for a peer according to the parameters collected by the system either from the user himself through a questionnaire or through user interaction with the system.

\subsubsection{MAS-PLANG}

MAS-PLANG is system that aims to offer characteristic of adaptability based on styles of learning for supporting distance adaptive education via the Web [41]. This system is based on the FIPA compliant multi-agent system, using Java, JavaScript Flash and XML languages. It provides content, navigation strategy, and navigation tools according to the students learning style. The environment is composed of two levels of agents: those of the higher level agent programmable (SONIA, Synthetic SMIT, Monitors, and Surfing), and the lower level (didactic agent, user).

- Sonia Agent: is a simple reflective agent that for its operation uses data for the tasks that the student or the professor wants it to carry out, as well as certain events happening in the learning environment.

- Navigation agent: organizes the navigation paths by direct interaction with databases and by communicating with the didactic agent and the user agent.

- Synthetic agent: presents the messages coming from other agents, in the form of suggestions or warnings when the student exhibits special behavior during the learning activity.

- Supervisor Agent: monitors the performance of JADE platform and other agents.

- User Agent: builds and maintains the student model.

- Didactic Agent: is based on information provided by the user agent to select the appropriate pedagogical strategies for the organization of the learning resources.

- Exercise Action Monitor: monitors the student during the exercise solving processes.

- General Action Monitor: monitors the action of its user and update the user agent.

- Pedagogic Agent: evaluates the pedagogic decision rules, whenever student interaction with materials.

- Controller Agent: Controls the operation of the agents that are assigned to the students or teacher during the learning session.

- Exercise Adapter Agent: Builds the exercise according to the requirement of the student.

\subsection{6. $S A C A$}

SACA is a Collaborative Learning System based on Agents, it is developed by Lafifi [42]. Its role is to measure the degree of assimilation of knowledge by learners. The different pedagogical activities, including learning, evaluation and of course collaboration are all realized using artificial agents. The assistant agent of the learner can assist him in his learning task (history, statistics, etc.). For its part, the assessment officer takes charge of the process of assessing the degree of assimilation of the knowledge of his learner. In SACA, learner modeling aims to construct a student model based on the observation of its behavior vis-à-vis the interface of a computer system.

SACA is composed of a number of artificial agents:

- Assistant Learner Agent: provides the learner with an interface that facilitates the learning task. He holds the learner model of the student, his learning history and his collaboration and evaluation history. The student model provides the information needed to understand learner progress and increase his learning and collaboration opportunities.

- Pedagogical Agent: His role is to choose the pedagogical objectives to present to the learner by relying on the state of knowledge of the learner (student model), the final level to be reached (final profile) and the favorable educational strategy.

- Collaboration Agent or Mediator: This agent can support the collaborative process between learners (collaboration request, search for a collaborator, choice of collaboration tool, etc.). It can negotiate a possible collaboration with the collaborating agents (mediators) of the other learners.

- Evaluation Agent: aims to measure the level of knowledge of the learner by offering a set of exercises of different models and varying difficulties. He is asked to verify the acquisition, by the learner, of the knowledge of an educational objective of the subject to be taught.

\subsection{Measurement criteria required for a system}

\subsubsection{Intelligent Agents Interaction in System}

The emergence and development of digital communication tools, which use the Internet network, make possible a faster and more frequent interaction between the tutor and the learner or between the different learners. This interaction is essential to enhance learning communities that enable learners to develop interpersonal skills, and to investigate tacit knowledge shared by community members as well as a formal curriculum. It can deal with the possibility of interaction between humans and agents, checking the possibility of asking for help and collaborating with an appropriate group with a large number of varieties and format that include asynchronous and synchronous communication using text, audio, and video.

\subsubsection{Adaptability Measurement of e-Learning Systems}

According to the third section, in order to have an effective 
educational system, it must no longer be stable with fixed content for all users, but it should respect all the changes made to the user model for building dynamic content. For this reason Brusilovsky [24] has defined the high-level methods for supporting adaptive hypermedia and the lower level techniques that are used to realize or implement this support [1]. Fig.3 and Fig.4 indicate the breakdown of adaptive navigation and presentation techniques appropriate to an adaptive hypermedia system.

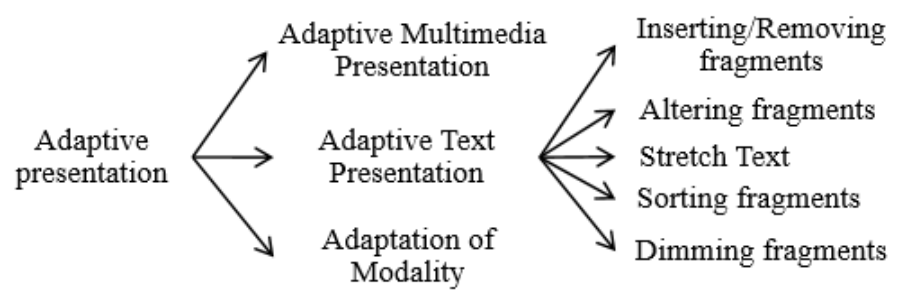

Figure 3 : Taxonomy of adaptive presentation technologies [33].

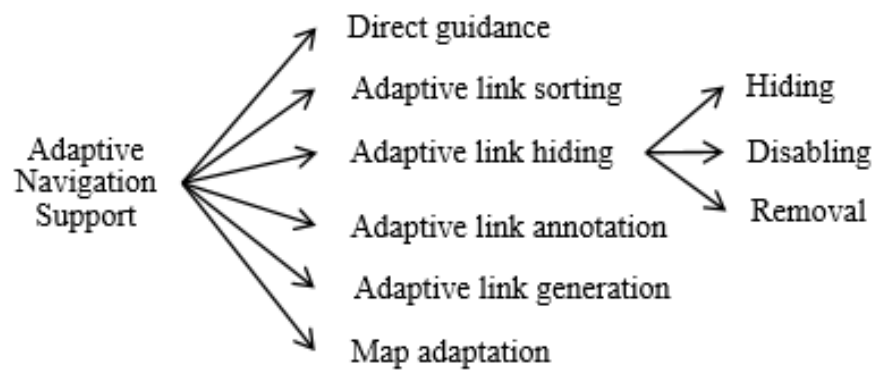

Figure 4: Taxonomy of adaptive Navigation Support technologies [33].

We will use the previously declared systems to analyze their adaptability based on the set of usable techniques.

\subsubsection{Cognitive Student Model}

This part presents how a student can manage his learning based on the assumption that no one learns exactly the same way. It aims to verify the degree of effectiveness of learner models of existing collaborative intelligent systems based on the nature of the learner characteristics represented. I.e. to check whether it is cognitive characteristics, meta-cognitive or only the representation of demographic information and some tests on the prerequisites of the learner. Cognitive Student Model designates the individual's way of perceiving, evoking, memorizing, and thus understanding the information perceived. This technique aims to use the characteristics defined previously in the learner profile (the duration of reading a page, number of consultation of a course page, the number of repetition of a QCM, etc.) in order to adapt the platform to the learner, to process and store new knowledge.

\subsubsection{Learner /group of learners follow up}

Unlike face-to-face learning spaces, where the teacher corrects at every moment all information circulating in the classroom during the collective exchange of knowledge. In distance learning environments, it is totally different, sometimes a student may propose involuntarily a false knowledge, or provide knowledge that does not meet the needs of his colleague. Because of a large number of learners connecting to the platform coupled with the high amount of tasks assigned to tutors, sometimes it will be very difficult to check all information shared between learners in different collaborative tools. For those reasons, it is so essential for each learner agent or group of learners' agent to evaluate the help offered by the system or by other learners during the collaboration.

\subsubsection{Security Measurement of e-Learning System}

Computer security, in general, plays the most important role which is to ensure that an organization's hardware or software resources of an e-Learning system are only used within the intended framework. The aim of security is to protect the most critical information for the conduct of learning activities in order to maintain the trust of learners and also other actors. It is therefore essential to protect them against intrusions and unauthorized access like:

- Protection of passwords, registration procedures and password recovery;

- Access control of learners;

- Content protection against copying;

- Securing exams online;

- $\quad$ Protection of private data related to users;

- Traceability of content, educational activities and sensitive administrative operations through electronic signature and audit mechanisms for highly regulated sectors;

- Backup and restoration of data in the event of a technical incident, etc.

In general, IT security is based on six main objectives:

- Authentication: ensuring that only authorized persons have access to resources;

- Authorization: provides permission to perform a security function or activity. This security service is often supported by a cryptographic service.

- Integrity: aims to ensure that data cannot be modified in an unauthorized or undetected manner;

- Confidentiality: ensuring that only authorized persons have access to the resources exchanged. Any unwanted access must be prevented;

- Non-repudiation: ensuring that a transaction cannot be denied;

- Availability: aims to maintain the proper functioning of the information system and ensure access to installed services and resources with the expected response time;

\subsection{Comparison of Existing systems}

In the following table, we will analyze and compare some existing environments dedicated to collaborative e-Learning based on multi-agent systems according to the criteria described above. 
Table 1: Comparative measurements between existing intelligent collaborative systems

\begin{tabular}{|c|c|c|c|c|c|c|c|}
\hline \multicolumn{2}{|c|}{ Measurements $\quad$ Systems } & ALLEGRO & BAGHERA & I-MIND & MASCE & MAS-PLANG & SACA \\
\hline \multirow{2}{*}{$\begin{array}{l}\text { Collaboration } \\
\text { Tools }\end{array}$} & Synchronous & $\begin{array}{l}\text { Chat and video } \\
\text { Conference }\end{array}$ & Chat & $\begin{array}{l}\text { Chat rooms and } \\
\text { Whiteboards }\end{array}$ & Chat & Chat & Chat \\
\hline & Asynchronous & Email & $\mathrm{X}$ & Forum & Email & Email & $\begin{array}{l}\text { Email and } \\
\text { Forum }\end{array}$ \\
\hline \multicolumn{2}{|c|}{ Intelligent actors Interaction } & $\begin{array}{l}\text { A student agent } \\
\text { is interacting } \\
\text { with the Teacher } \\
\text { tutor agent, } \\
\text { Collaborative } \\
\text { agent and } \\
\text { Expert Agent }\end{array}$ & $\begin{array}{l}\text { A student interacts } \\
\text { with three } \\
\text { artificial agents: } \\
\text { Companion, Tutor } \\
\text { and Mediator; } \\
\text { A teacher interacts } \\
\text { with two artificial } \\
\text { agents: } \\
\text { Companion and } \\
\text { Assistant }\end{array}$ & $\begin{array}{c}\text { The student } \\
\text { agent manages } \\
\text { the } \\
\text { communication } \\
\text { channels among } \\
\text { students and } \\
\text { between the } \\
\text { teacher and the } \\
\text { students }\end{array}$ & $\begin{array}{l}\text { Each student is } \\
\text { interacting with } \\
\text { the } \\
\text { corresponding } \\
\text { Student } \\
\text { Manager Agent } \\
\text { that helps the } \\
\text { learning process } \\
\text { of the student }\end{array}$ & $\begin{array}{l}\text { Student interact } \\
\text { with different } \\
\text { agents (SONIA, } \\
\text { Monitoring agents, } \\
\text { programmed } \\
\text { agents...) }\end{array}$ & $\begin{array}{c}\text { Learner interacts } \\
\text { with the Learner } \\
\text { Assistant Agent } \\
\text { Teacher is } \\
\text { interacting with a } \\
\text { Teacher Assistant } \\
\text { Agent and Teacher's } \\
\text { Mediator Agent } \\
\text { Tutor is associated } \\
\text { with a Tutor Agent }\end{array}$ \\
\hline \multirow{2}{*}{$\begin{array}{l}\text { Adaptability } \\
\text { Measurement }\end{array}$} & Navigation & $\mathbf{X}$ & $\begin{array}{l}\text { Adaptive link } \\
\text { annotation }\end{array}$ & Guidance direct & $\mathbf{X}$ & $\begin{array}{l}\text { Adaptive link } \\
\text { hiding }\end{array}$ & $\begin{array}{l}\text { Adaptive link } \\
\text { annotation }\end{array}$ \\
\hline & Presentation & $\begin{array}{l}\text { Inserting / } \\
\text { Removing } \\
\text { fragments }\end{array}$ & $\mathbf{X}$ & $\mathbf{X}$ & $\begin{array}{l}\text { Inserting / } \\
\text { Removing } \\
\text { fragments }\end{array}$ & $\mathbf{X}$ & $\mathbf{X}$ \\
\hline \multicolumn{2}{|c|}{ Cognitive Student Model } & $\begin{array}{l}\text { Student model } \\
\text { contemplates } \\
\text { the learning } \\
\text { style, } \\
\text { understanding } \\
\text { of the subjects, } \\
\text { limitations and } \\
\text { knowledge level } \\
\text { of the } \\
\text { apprentice. }\end{array}$ & $\mathbf{X}$ & $\mathbf{X}$ & $\begin{array}{l}\text { MASCE makes } \\
\text { it possible to } \\
\text { present } \\
\text { relatively some } \\
\text { preferences such } \\
\text { as cognitive } \\
\text { style (maximum } \\
\text { numbers of } \\
\text { concurrent } \\
\text { discussions) }\end{array}$ & $\mathbf{X}$ & $\begin{array}{l}\text { In this system, the } \\
\text { cognitive level } \\
\text { represents only the } \\
\text { knowledge, and } \\
\text { moreover, it is the } \\
\text { learner who must } \\
\text { manually choose his } \\
\text { value (excellent, } \\
\text { good, average, etc.). }\end{array}$ \\
\hline \multicolumn{2}{|c|}{$\begin{array}{l}\text { Learner /group of learners follow } \\
\text { up }\end{array}$} & $\mathbf{X}$ & $\mathbf{X}$ & $\begin{array}{l}\text { I-MINDS } \\
\text { student agent } \\
\text { evaluates and } \\
\text { forms a peer } \\
\text { group ("buddy } \\
\text { group") for the } \\
\text { student that it } \\
\text { serves }\end{array}$ & $\begin{array}{l}\text { After each help } \\
\text { session, each of } \\
\text { the helper and } \\
\text { helpee are } \\
\text { provided with } \\
\text { an evaluation } \\
\text { form to evaluate } \\
\text { his peer. }\end{array}$ & $\mathbf{X}$ & $\mathbf{X}$ \\
\hline \multirow{6}{*}{$\begin{array}{l}\text { Security } \\
\text { Measurement }\end{array}$} & Authentication & $\mathbf{X}$ & $\begin{array}{l}\text { The application } \\
\text { home page } \\
\text { requires users } \\
\text { (student, teacher, } \\
\text { or administrator) } \\
\text { to login to access } \\
\text { their own } \\
\text { interfaces }\end{array}$ & $\begin{array}{l}\text { Student connect } \\
\text { for each of the } \\
\text { classrooms } \\
\text { using login and } \\
\text { password }\end{array}$ & $\begin{array}{l}\text { Student logs to } \\
\text { the system and } \\
\text { is given a user } \\
\text { name and a } \\
\text { password for } \\
\text { authentication in } \\
\text { a specific } \\
\text { course. }\end{array}$ & $\begin{array}{l}\text { A student must be } \\
\text { connected to the } \\
\text { system to have } \\
\text { access to revise } \\
\text { some specific } \\
\text { sections of the } \\
\text { lesson, solve a } \\
\text { particular problem } \\
\text { or enter the chat } \\
\text { room. }\end{array}$ & $\begin{array}{l}\text { Learners, authors } \\
\text { and tutors must } \\
\text { register before any } \\
\text { effective use of the } \\
\text { system }\end{array}$ \\
\hline & Authorization & $\mathbf{X}$ & $\mathbf{X}$ & $\mathbf{X}$ & $\mathbf{X}$ & $\mathbf{X}$ & $\mathbf{X}$ \\
\hline & Integrity & $\mathbf{x}$ & $\mathbf{X}$ & $\mathbf{X}$ & $\mathbf{X}$ & $\mathbf{X}$ & $\mathbf{X}$ \\
\hline & Confidentiality & $\mathbf{X}$ & $\mathbf{X}$ & $\mathbf{X}$ & $\mathbf{X}$ & $\mathbf{X}$ & $\mathbf{X}$ \\
\hline & Non-repudiation & $\mathbf{X}$ & $\mathbf{X}$ & $\mathbf{X}$ & $\mathbf{X}$ & $\mathbf{X}$ & $\mathbf{X}$ \\
\hline & Availability & $\mathbf{X}$ & $\mathbf{X}$ & $\mathbf{X}$ & $\mathbf{X}$ & $\mathbf{X}$ & $\mathbf{X}$ \\
\hline
\end{tabular}




\subsection{Analysis and prospect for improvements}

Reviewing the existing intelligent collaborative systems, we have seen that they have advantages as they have limits. But generally, we can see that they are hardly trying to solve the problem of students' drop out through the integration of certain information and communication techniques to benefit from his strength. If we analyze the table above, we can mention that most of these systems are reinforced by the involvement of many collaborative tools, whether synchronous tools such as chat, or asynchronous tools like email, Whiteboard and forum discussion. Particularly, this can be retained as a great benefit in online learning systems, but this is not always the case. Indeed, the majority of these systems offer certain collaborative tools for learners to work in groups without verification whether this collaboration is beneficial and may meet the needs and preferences of the learner, thus, simply put two people in contact does not necessarily guarantee a good result. Therefore, collaborative tools can have adverse effects if the system does not control the learner behavior. In most cases, learners spend all their time communicating with other colleagues off the topic of learning. For this reason, the system must be managed against the misuse of collaboration tools so that it does not lose its educational value. Further, the majority of these systems are interested in collaborative learning in groups, but they have never analyzed how these groups should be constituted even there have been several studies conducted on the ideal size of the group, and methods of choosing members for regrouping.

As we have already shown in the third section of this article, the integration of agents in an e-Learning system suggests a very important improvement. It makes agents able to diminish and facilitate tasks to all human actors of learning platform. In order to have a more efficient learning environment, it is recommended to separate the tasks of different actors in the platform. I.e. it is better to have a system with multiple agents where everyone is responsible for specific tasks, instead of having, for example, one tutor or teacher agent who take overall responsibility for managing the whole system. So, in an e-Learning system, it's better to separate the teacher role for two or more actors such as the pedagogical author and the expert author. Where the pedagogical author (or instructional designer) utilizes all the pedagogical design principles, models, and learning theories available to achieve pedagogical goals as he supports the management and development of e-Learning course content, the creation of storyboards, development compliance manuals, etc. While the expert author tries to define what needs to be added to the eLearning course, and what can be put aside. Most of the time, a different expert author is used for each new e-Learning course. He usually works closely with the instructional designer to determine the key points and learning objectives of the course, as well as how the content will be delivered. Similarly to the tutor agent, it is necessary to separate the maximum tasks by creating specific agents such as the filtering agent that allows filtering multimedia documents stored in e-Learning system's database in order to select an appropriate educational content adapted to the criteria specified in the student model. Or the technical assistant agent that is responsible for the good technical functioning, and the necessary updates in the learning environment. He must always be available to help learners if they have a technical problem, or if they do not master the use of the computer tools.

From the table 1, we can observe that the personalization applied in these systems does not exceed more than one aspect of adaptation, i.e. they only adapt the navigation or the presentation of the interfaces. Moreover, they are limited to the use of just one adaptation technique, which is often inserting and removing fragment for presentation adaptation, and the adaptive annotation for navigation adaptation Indeed, this adaptation remains insufficient in the most existing systems and make their interfaces so very poor ergonomically. So we can summarize that there is a lack in the adaptation that should not be left behind.

This analyze, we noted that the problem of the lack of adaptation techniques used is not the only obstacle that interferes with the flexibility of adaptation of those systems, but there is also the lack of learner modeling. Most distance learning systems have been structured with a minimum of consideration of relevant aspects of human cognitive architecture [43]. Each of them does not perform any user model representations while others offer a limited learner model such as SACA for example. It deals only with the acquisition of learner's knowledge whereas learner modeling is no longer limited to modeling knowledge but also the representation of psychological aspects such as information on the emotional state and emotions, the intentions of the learner. In this system, the cognitive aspects can only be dealt with a simple question asked to the user aiming to specify the level of mastery of concept taught. Before starting the learning activity, the learner must manually indicate his level of knowledge using a simple value (excellent, good, average ...), which is still irrelevant. For the above reasons, it's important to think about improving existing systems or to design a new system based on cognitive modeling of the learner, i.e. it aims to represent as closely as possible all the cognitive and metacognitive aspects relating to the behaviors of a learner.

Not only misuse of cognitive student model but also the problem of helps evaluation by Learner agent or group of learner agent. We can distinguish that MASCE allows a learner to ask for help and to evaluate the help provided by another learner, and IMINDS allows the teacher to monitor the activities of learners and groups. And both systems are used to evaluate learners. Unlike MASCE, I-MINDS offers users the possibility of forming a group [39]. However, the others do not offer any follow-up of learners.

Concerning the systems analyzed above, we can notice that the most of them lack the most basic conditions to prevent intruders. While the evolution of educational systems via the Internet currently is leading to a new concept of security threats against applications and users that affect e-Learning content design and tools. Besides that, even other systems that are partially secure, they only protect the authentication problem like MASCE, MASPLAN, and I-MINDS. Indeed, when designing a secure e-Learning system, designers must have a clear idea of the threats they must prevent, and the technical capabilities of the attackers to specify accordingly the preliminary steps required to secure the system [44]. They must take into consideration the identification verification of the student being assessed by ensuring that the person answering is the learner who must have passed the assessment and not another person. They must also protect the e- 
Learning systems, especially when passing evaluation, against nodes and links attacks which affects the availability of evaluation pages and other resources [44]. In the same way, the system must be protected by preventing unwanted access and theft of documents that reveal user privacy information. In addition, they must secure the evaluation procedures by ensuring that the learners did not have access to the assessment procedures before taking the exam. Indeed, in an e-Learning environment, depending on time zones, some students can take their exam in one country while others are still reviewing. This problem does not matter for environments that just have awareness training on a subject, but they are more important for certified training. And as a result, that will affect the reputation of the risky platform, and negatively affect the quality of the degrees acquired. For that, the most likely attacks for these systems should be described independently of the specific implementation, to help designers to eliminate or mitigate these attacks if possible in the design phase not waiting for actual attacks to occur.

\section{Conclusion}

According to the originality of solutions offered by adaptive multi-agent systems, recently, e-Learning researchers often use MAS to solve many problems as selecting autonomously the most suitable learning objects that meet students' preferences, or collecting and processing learners' data in order to monitor their progress, motivate and guide them, and avoid their abandonment. In this study, we present the interest of artificial intelligence in eLearning system for the purpose of controlling the students' dropout phenomenon. We analyzed some existing intelligent collaborative e-Learning based on various characters in order to determine their limits and propose some improvement that can make them more reliable for use.

In this paper which represent an analysis of some existing intelligent collaborative systems, we concluded that these systems are still in need of improvement at the level of integration of a powerful learner model. This model should not be limited to a simple collection of learner biographical information or an assessment of learner level knowledge, but it must also be able to represent psychological aspects such as information on affective state and emotions, learner intentions, as well as cognitive and metacognitive characteristics. We found also that the most of the analyzed systems do not offer any follow-up of learners. Moreover, the lack of the most basic conditions to prevent intruders even the other systems that are partially secure, they only protect the authentication problems.

\section{References}

[1]. CLARK, Ruth C. and MAYER, Richard E. E-learning and the science of instruction: Proven guidelines for consumers and designers of multimedia learning. John Wiley \& Sons, 2016.

[2]. OYE, N. A., IAHAD, N., MADAR, M. J., and al. The impact of e-learning on students' performance in tertiary institutions. International Journal of Computer Networks and Wireless Communications, 2012, vol. 2, no 2, p. 121-130.

[3]. BELANGER, Yvonne and THORNTON, Jessica. Bioelectricity: A quantitative approach Duke University's first MOOC. 2013.

[4]. HALAWA, Sherif, GREENE, Daniel, and MITCHELL, John. Dropout prediction in MOOCs using learner activity features. Experiences and best practices in and around MOOCs, 2014, vol. 7, p. 3-12.

[5]. ONAH, Daniel FO, SINCLAIR, Jane, and BOYATT, Russell. Dropout rates of massive open online courses: behavioural patterns. EDULEARN14 proceedings, 2014, p. 5825-5834.
[6]. GÜTL, Christian, RIZZARDINI, Rocael Hernández, CHANG, Vanessa, and al. Attrition in MOOC: Lessons learned from drop-out students. In International Workshop on Learning Technology for Education in Cloud. Springer, Cham, 2014. p. 37-48. https://doi.org/10.1007/978-3-319-1067174

[7]. GEE, Sue. MITx-the fallout rate. Message posted, 2012, vol. 16.

[8]. BARKLEY, Elizabeth F., CROSS, K. Patricia, and MAJOR, ClaireH. Collaborative learning techniques: A handbook for college faculty. John Wiley \& Sons, 2014.

[9]. ASSELMAN, Amal, NASSEH, Az-Eddine, and AAMMOU, Souhaib. Survey of intelligent collaborative E-learning systems. In: Emerging eLearning Technologies and Applications (ICETA), 2017 15th International Conference on. IEEE, 2017. p. 1-7. 10.1109/ICETA.2017.8102463

[10]. ZAPPAROLLI, Luciana Silva and STIUBIENER, Itana. FAG-a management support tool with BI techniques to assist teachers in the virtual learning environment Moodle. Advances in Science, Technology and Engineering Systems Journal, 2017, vol. 2, no 3, p. 587-597. 10.25046/aj020375

[11]. DE KOCH, Nora Parcus. Software engineering for adaptive hypermedia systems. Ph. DThesis, Verlag Uni-Druck, Munich, 2001.

[12]. JÄrVELÄ, Sanna, KIRSCHNER, Paul A., PANADERO, Ernesto, and al. Enhancing socially shared regulation in collaborative learning groups: designing for CSCL regulation tools. Educational Technology Research and Development, 2015, vol. 63, no 1 , p. 125-142. https://doi.org/10.1007/s11423-014-9358-1

[13]. ROSCHELLE, Jeremy. Learning by collaborating: Convergent conceptual change. The journal of the learning sciences, 1992, vol. 2, no 3, p. 235-276. https://doi.org/10.1207/s15327809jls0203 1

[14]. WALCKIERS, Marc and DE PRAETERE, Thomas. L'apprentissage collaboratif en ligne, huit avantages qui en font un must. Distances and savoirs, 2004, vol. 2, no 1, p. 53-75. 10.3166/ds.2.53-75

[15]. MCLAREN, Bruce M., SCHEUER, Oliver, and MIKŠÁTKO, Jan. Supporting collaborative learning and e-Discussions using artificial intelligence techniques. International Journal of Artificial Intelligence in Education, 2010, vol. 20, no 1, p. 1-46.

[16]. MCCARTHY, John, MINSKY, Marvin L., ROCHESTER, Nathaniel, and al. A proposal for the dartmouth summer research project on artificial intelligence, august 31, 1955. AI magazine, 2006, vol. 27, no 4, p. 12.

[17]. RUSSELL, Stuart J. and NORVIG, Peter. Artificial intelligence: a modern approach. Malaysia; Pearson Education Limited, 2016.

[18]. WENGER, Etienne. Artificial intelligence and tutoring systems: computational and cognitive approaches to the communication of knowledge. Morgan Kaufmann, 2014.

[19]. BRUSILOVSKY, Peter. Methods and techniques of adaptive hypermedia. User modeling and user-adapted interaction, 1996, vol. 6, no 2-3, p. 87-129. https://doi.org/10.1007/BF00143964

[20]. MIHALCA, Rodica, UTA, A., ANDREESCU, Anca, and al. Knowledge management in E-learning systems. Revista Informatica Economică, 2008, vol. 2 , no 46, p. 60-65.

[21]. GHAHRAMANI, Zoubin. Probabilistic machine learning and artificial intelligence. Nature, 2015, vol. 521, no 7553, p. 452.

[22]. WOOLDRIDGE, Michael. An introduction to multiagent systems. John Wiley \& Sons, 2009.

[23]. RUSSELL, Stuart and NORVIG, Peter. Intelligence artificielle: Avec plus de 500 exercices. Pearson Education France, 2010.

[24]. CHAIB-DRAA, Brahim, JARRAS, Imed, and MOULIN, Bernard. Systèmes multi-agents: principes généraux and applications. Principes and architectures des systèmes multi-agents, 2001.

[25]. LABIDI, Sofiane and LEJOUAD, Wided. De l'intelligence artificielle distribuée aux systèmes multi-agents. 1993. Thèse de doctorat. INRIA.

[26]. FERBER, Jacques. Les systèmes multi-agents: vers une intelligence collective. InterEditions, 1995.

[27]. ASSELMAN, Amal, AAMMOU, Souhaib, and NASSEH, Az-Eddine. Comparative study of cognitive architectures. International Research Journal of Computer Science (IRJCS), 2015, vol. 2, no 9.

[28]. ANDERSON, John R. How can the human mind occur in the physical universe? Oxford University Press, 2009.

[29]. KOTSERUBA, Iuliia, GONZALEZ, Oscar J. Avella, and TSOTSOS, John K. A review of 40 years of cognitive architecture research: focus on perception, attention, learning and applications. arXiv preprint arXiv:1610.08602, 2016.

[30]. BISWAS, Pradipta and SPRINGETT, Mark. User Modeling. The Wiley Handbook of Human Computer Interaction, 2018, vol. 1, p. 143-169. https://doi.org/10.1002/9781118976005.ch8

[31]. VAN RIJN, Hedderik, JOHNSON, Addie, and TAATGEN, Niels. Cognitive user modeling. Handbook of human factors in web design, 2nd edn. CRC Press, New Yersey, 2011, p. 527-542. http://doi.org/doi:10.1201/b10855-34

[32]. BRUSILOVSKY, Peter and MILLÂN, Eva. User models for adaptive hypermedia and adaptive educational systems. In: The adaptive web. Springer 
Berlin Heidelberg, 2007, vol. 4321, p. 3-53. https://doi.org/10.1007/978-3540-72079-9 1

[33]. BRUSILOVSKY, Peter. User modeling and user-adapted interaction. 2001.

[34]. CHEN, Sherry Y. and MAGOULAS, George D. (ed.). Adaptable and adaptive hypermedia systems. IGI Global, 2005.

[35]. AL-AZAWEI, Ahmed and BADII, Atta. State of the art of learning stylesbased adaptive educational hypermedia systems (LS-BAEHSs). International Journal of Computer Science \& Information Technology, 2014, vol. 6, no 3, p. 1. http://dx.doi.org/10.5121/ijcsit.2014.6301

[36]. KORB, Kevin B. and NICHOLSON, Ann E. Bayesian artificial intelligence. CRC press, 2010.

[37]. VICCARI, Rosa M., OVALLE, Demetrio A., and JIMÉNEZ, Jovani A. ALLEGRO: Teaching/learning multi-agent environment using instructional planning and cases-based reasoning (CBR). CLEI Electronic Journal, 2007, vol. 10 , no 1 , p. 1-20.

[38]. WEBBER, Carine, BERGIA, Loris, PESTY, Sylvie, and al. The Baghera project: a multi-agent architecture for human learning. In: Workshop-MultiAgent Architectures for Distributed Learning Environments. In Proceedings International Conference on AI and Education. San Antonio, Texas. 2001.

[39]. SOH, Leen-Kiat, KHANDAKER, Nobel, and JIANG, Hong. IMINDS: a multiagent system for intelligent computer-supported collaborative learning and classroom management. International Journal of Artificial Intelligence in Education, 2008, vol. 18, no 2, p. 119-151.

[40]. MAHDI, Hani and ATTIA, Sally S. MASCE: a multi-agent system for collaborative e-learning. In: Computer Systems and Applications, 2008. AICCSA 2008. IEEE/ACS International Conference on. IEEE, 2008. p. $925-$ 926. 10.1109/AICCSA.2008.4493647

[41]. PEÑ A, Clara-Inés, MARZO, Jose-L., and DE LA ROSA, JosepLluis. Intelligent agents in a teaching and learning environment on the Web. In: Proceedings of the international conference on advanced learning technologies. Palmerston North, NZ: IEEE Learning Technology Task Force. 2002. p. 21-27.

[42]. LAFIFI, Yacine. SACA: un Système dApprentissage Collaboratif. 2007. Thèse de doctorat. $\mathrm{PhD}$ Thesis, Computer science department, University of Annaba, Algeria.

[43]. BALAŽ, Zdenko and PREDAVEC, Davor. Cognitive Cybernetics vs. Captology. Advances in Science, Technology and Engineering Systems Journal, 2017, vol. 2, no 6, p. 107. 10.25046/aj020614

[44]. NICKOLOVA, Maria and NICKOLOV, Eugene. Threat model for user security in e-learning systems. International Journal Information Technologies and Knowledge, 2007, vol. 1, no 1, p. 341-347. 